\title{
FABLA MODERNISTA EN FABLA SALVAJE DE CÉSAR VALLEJO
}

\section{Eduardo Hopkins Rodríguez}

Pontificia Universidad Católica del Perú

efhopkins@gmail.com

Resumen: Se estudia la novela corta Fabla salvaje (1923) de César Vallejo, proponiendo una interpretación del concepto de fabla vinculada a relato, a una visión fatalista de la naturaleza y al estilo del narrador en sus relaciones con el modernismo hispanoamericano.

Palabras clave: Fabla salvaje, novela corta, interpretación, estilo, modernismo.

\section{MODERNIST FABLA IN FABLA SALVAJE BY CÉSAR VALLEJO}

Abstract: The short novel Fabla salvaje (1923) by César Vallejo is studied proposing an interpretation of the concept of fabla linked to narration, a fatalistic vision of nature and the style of the narrator in its relationship with Hispanic American modernism.

Keywords: Fabla salvaje, short novel, interpretation, style, modernism.

DOI: $\underline{\text { https://doi.org/10.24029/lejana.2020.13.438 }}$

Recibido: el 2 de noviembre de 2018

Aceptado: el 1 de marzo de 2019

Publicado: el 19 de febrero de 2020 
En 1923 César Vallejo publicó su novela corta Fabla salvaje. ${ }^{1}$ Fabla es un arcaísmo utilizado en la tradición española desde la Edad Media. En primer lugar, equivale a relato, cuento. Es término familiar en el caso de la juglaresca medieval, particularmente asociado a la épica en tanto enunciación independiente, o como exordio que cumple la función de presentar el canto de hechos heroicos (Díaz Viana: 100-101). Vallejo lo había aplicado con anterioridad a su novela en el poema de temática histórica en elogio del Marqués de Torre Tagle titulado "Fabla de gesta" (1920), ${ }^{2}$ que obtuvo un segundo premio en un concurso literario convocado en la ciudad de Trujillo. "Fabla de gesta" es un título que señala claramente su resonancia épica medieval. Por otro lado, fabla también significa habla, conversación, manera de hablar, lengua. En el Poema de Mio Cid, se emplea como discurso: "fablo mio Cid bien e tan mesurado" (7). Dice Juan Ruiz en El libro de buen amor: "En general a todos fabla la escriptura" (67a). En Romance de lobos (1908), de Ramón del Valle Inclán, El Ciego de Gondar dice: "y una fabla que he de tener contigo, Andreíña" (71). Duque, novela del escritor peruano José Diez-Canseco, escrita entre 1928 y 1929 y publicada en 1934, registra: "fabla insinuante" (142), "fabla cruda" (156).

En la novela de Vallejo, el sentido directo de fabla nos remite, en primer lugar, a relato de un suceso extraordinario. En una segunda instancia, concierne a un habla recóndita que proviene de la naturaleza. Consideramos que una tercera posibilidad de lectura del concepto de fabla radica en el hecho de resaltar la forma característica en que se configura la enunciación del narrador.

Fabla salvaje presenta una estructura expositiva clara dividida en ocho partes de corta extensión. La novela da inicio inmediato al problema del protagonista, y cada sección está concentrada en desarrollar específicamente la temática correspondiente al conflicto del personaje. Balta Espinar cree que hay alguien desconocido en su entorno. Se trata de una presencia inquietante, sin identidad, elusiva, extraña, amenazante, un intruso que genera paranoia, temores, sospechas y celos en Balta, alterando el equilibrio de su integridad personal. Balta caerá a un abismo asustado por el roce de una presencia en su espalda. El mismo día nace su hijo, quien también muere pocas horas después. Curiosamente, tanto lectores críticos como aquellos menos expertos invariablemente construyen una simetría compensatoria al imaginar que el hijo recién nacido equilibra la desaparición del padre. ${ }^{3}$ Gusta el final melodramático, pleno de relaciones psicoanalíticas, tales como el complejo de Edipo, en el que se involucra el temor del padre a ser sustituido por el hijo, etc. No se observa que en el párrafo final de la novela se anuncia, en una atmósfera numinosa, la muerte del niño. El padre, al no desear la paternidad, pues se la atribuye al otro extraño, niega su continuidad genética. La familia no será posible. Desde otra perspectiva, vemos que Balta es invadido progresivamente por el desequilibrio mental. Esto plantea la necesidad de una interrupción en la secuencia hereditaria malsana. La muerte del recién nacido implica que la cadena vital debe ser un proceso sin rupturas, sin alteraciones catastróficas. Este final es cruel, y es trágico. Posee, además, mayor densidad significativa.

\footnotetext{
${ }^{1}$ Citamos de César Vallejo, Narrativa completa. Lima, Pontificia Universidad Católica del Perú, 1999.

${ }^{2}$ César Vallejo. Poemas completos. 1998: 260-261.

${ }^{3}$ En la lectura acerca del final del relato que equilibra la muerte de Balta con el nacimiento del niño, coinciden, por ejemplo, Ricardo Silva-Santisteban, Birger Angvik, Gisela Jöerger, Mara L. García, Antonio González Montes, Ricardo González Vigil, Alain Sicard, Robert K. Britton.
} 
La rotura de un espejo: “¡alguna desgracia!” (152), el canto de una gallina: "qué va a ser de nosotros", "mala suerte, mala suerte" (152), constituyen acontecimientos interpretados como anuncios de mal agüero por Balta y su esposa Adelaida, iniciando la atmósfera de presagios de la novela desde la perspectiva de las creencias de su propia tradición cultural andina. El narrador, por su parte, se encargará de acentuar el tono premonitorio del relato convocando conceptos trágicos y fatalistas, mediante un típico lenguaje cultista.

En principio, el narrador examina los sucesos en términos de tragedia: "La tragedia empezaba, pues, a apolillar, de tal manera, a ocultas, y capa a capa, de la médula para afuera, aquel duro y milenario alcanfor que hace de viga céntrica suspenso de largo en largo, a modo de espina dorsal, en el techo del hogar" (163-164).

El alcanfor es un árbol longevo, que aparece en otras zonas del espacio de la acción (151, 158, 160), fuera del ámbito de la casa familiar. Su presencia connota antigüedad, amplitud temporal, sentido de lo remoto, permanencia. En la novela, el alcanfor es madera que sostiene la casa y contiene el germen de la tragedia, como elemento supratemporal, latente:

La tragedia aquel día abandonó la médula del alcanfor milenario, que hace de viga central en el hogar, y, al morder el primer vaso capilar de los círculos internos de la zona de la madera, tropezó de pronto con un viejo parásito miserable que aún sobrevivía a la época sensible del árbol; le quiso despreciar la tragedia, y ya iba a internarse en el fibroso bosque, cuando el aire empezó a agitarse con violencia y quiso arrebatar el amplio sombrero de palma de Balta sobre la roca. La tragedia enmendóse, y a viva fuerza echó a sus lomos al intruso. (173)

La tragedia asume el designio superior de los vientos e incorpora en su periplo al mencionado parásito. Cuando retorna de su excursión, se reincorpora en el alcanfor: "La tragedia también acababa de volver a las internas capas de madera de la viga del hogar; volvía de arañar a deshora unos restos olvidados de corteza de aquel alcanfor secular; vagó por tales incisiones y, siempre con el viejo parásito miserable a cuestas, tornó y ocupó su lugar, destino en mano, dale y dale" (181).

No descansa en su labor destructora. La alegoría expone aquí a la tragedia usando el destino como herramienta de corrosión, acompañada por el inevitable y antiguo parásito. Con este último término el narrador se refiere al gusano de los celos: "unos celos sutiles, como frioleros y acerados picos, sacaron la cabeza y se arrebujaron en sus entrañas, con furtivo y azogado gusaneo montaraz" (171). Azogar es parte del proceso de fabricación de un espejo. Los gusanos que brillan y reflejan, multiplican los celos. Se trata de un parásito persistente, que solo morirá cuando desaparezca el ser humano. Recordemos que Vallejo consideraba que "es un hecho de vulgar observación que el parásito [...] se pudre juntamente con el ser que lo alimenta" (2002, 693). Cabe indicar que en el caso de Balta no hay una maldición mítica heredada o motivada por el personaje, como en la concepción de la tragedia griega. Tal maldición se halla en la naturaleza, desde una temporalidad remota, y puede elegir a cualquiera al azar.

Tragedia, destino, celos, cuentan con otro componente del universo trágico, el cual está constituido por las Moiras o Parcas, divinidades tejedoras de los hilos de la vida y el destino, cuya intervención surge veladamente en varias instancias del relato. Al respecto, el tema del hilo es esencial. Diversas alusiones a tejido, costura, hilo, hebra, pita, pabilo, rueca, aguja, llaman la atención hacia el tema clásico de las Parcas: “Aguja muy fina jugaba a lo 
largo de sus tensas venas y cosía ahí un recodo a otro, una papila firme y vibrátil a otra fugitiva, con dura pita negra que él nunca había visto brotar de los vastos pencales maduros... Era dura esa pita, y le hacía doler; y esa aguja erraba vertiginosamente en su sangre conturbada. Balta quería cogerla y se le escurría de los dedos" (157).

Hilo aparece también como sombra delgada: "Su sombra, una turbia sombra intermitente, la que, moviéndose a compás de su cuerpo, ya aparecía enorme, ancha, larga; ya se achicaba, ludíase hasta hacerse una hebra impalpable, o ya se escurría totalmente" (163).

Específicamente, hebra se halla vinculada a los celos en el siguiente pasaje: “¿Por qué, al contrario, junto a esa hebra torturadora, que no se sabe a dónde había de ir a insertarse, encendíase un granate desconocido entre los brazos de su amor?" (163).

En una noche de insomnio, Balta reflexiona como quien desenvuelve y enlaza hilos: "En medio del silencio de la noche, desbarquillaba fibra a fibra recuerdos de lugares, fechas, acontecimientos e imágenes, deduciendo relaciones, atando cabos sobre su posición actual en la vida" (168).

En cuanto a hilo asociado a fatalidad, encontramos: "Arrancarle una punta siquiera del hilo en que los dos estaban enredándose de modo irremediable y fatal" (174).

El niño Santiago, hermano de Adelaida, se pregunta: “¿qué haces, Adelaida? ¿Buscas tu rueca?" (177). La rueca, instrumento de las parcas dedicadas al tejido del destino, ausente ahora de la vida de Adelaida, señala su profunda desorientación respecto del marido.

La madre de Adelaida, Doña Antuca, está vinculada a la muerte, como la Parca Átropos, encargada de cortar con sus tijeras el hilo de la vida: "Díscola suegra ésta, media ciega de unas cataratas que cogió hacía muchos años, al pasar una medianoche, a solas, por una calle, en una de cuyas viviendas se velaba a la sazón un cadáver; el aire la hizo daño" (158).

Las asociaciones con la temática de las Parcas son fundamentales para comprender el final de la novela. En la habitación donde duerme el recién nacido, acompañado por la abuela Antuca, ocurre lo siguiente:

Un cirio que ardía ante el ara empezó a chorrearse; su pabilo giraba a pausas y en círculo, chisporroteando, y cuando la mano trémula de la abuela fue a despavesarlo y a arreglarlo, hallólo mirando largamente a la puerta que permanecía entornada al corredor. Llorando salía por allí la triste lumbre religiosa, hincábase a duras penas en los fríos pañales del poniente y ganaba por fin hacia lo lejos.

Era el mes de marzo y empezó a llover. (183)

Este final está cargado de alusiones a motivos vinculados con la temática de las Parcas: el pabilo o mecha del cirio ante el ara (elementos de índole religiosa), que gira como el huso en el hilado; la mano trémula de la anciana que, como una Parca, se dirige a quitarle la ceniza y a acomodarlo, sin llegar a cumplir su propósito, pues el hilo, orientado hacia la puerta medio abierta que conduce al corredor, proyecta su luz como extensión de su textura — "triste lumbre religiosa" - hacia el exterior, "llorando" al salir, hincándose (es decir, clavándose como una aguja) penosamente "en los fríos pañales del poniente" para llegar finalmente "hacia lo lejos". Los nexos de doña Antuca con la muerte quedaron señalados cuando el narrador indicó que se había quedado medio ciega al pasar por donde se velaba un cadáver. Aquí, fuego que arde, ara, pabilo que gira, mano trémula, puerta, luz que llora, religiosidad, hincar en pañales fríos (como pañales de cadáver), poniente, lejos, marcan la 
secuencia de un momento de paso: la muerte del recién nacido. La automatización que genera en el lector la expectativa de la alternancia entre muerte y vida, se ve frustrada ante la desaparición del hijo.

Otro mito de origen clásico, fundamental en la novela por las relaciones con espejo y reflejo, es el de Narciso y Eco. Balta significa charco, pozo o fuente. Lo cual tiene que ver con la materia acuática en la que suele mirarse: fuente, manantial, acequia. Categorías asociadas con este mito son las de repetición, serie, secuencia, continuidad. El espejo fragmentado genera en Balta ruptura, discontinuidad de la imagen. El reconocimiento de sí mismo se hace difícil. Se produce un bloqueo de la anagnórisis. Respecto de la voz de Adelaida, dice el narrador: "voz que en las entrañas de la basáltica peña índiga de enfrente tiene una hermana encantada, eternamente en viaje y eternamente cautiva... Así era la voz de Adelaida" (156). Se trata del eco de la voz de la joven esposa. Como "hermana encantada", recuerda a la ninfa Eco del mito de Narciso. Con "encantada", se juega con las connotaciones de canto, piedra, hechizo.

Ante los gritos de un pastor, el narrador anota:

Dio unos gritos melancólicos en el abismo, donde las herbosas quebradas rezumaban ya, y a sus gritos respondió el sereno peñasco majestuoso con el eco cavernoso y de encanto de la conciencia inorgánica; eco invisible y opaco y recocido, conque responde la dura piedra soberana a la cruda voz del Hombre; manera de espejo sonoro, en cuyo fondo impasible está escondida la simiente misteriosa e inmarchita de inesperadas imágenes y luces imprevistas... Acaso aquí habría hallado también Balta la propia resonancia, retorcida y escabrosa, la desconocida imagen que, ya en el espejo, ya en el manantial o en las corrientes, le acechaba y relampagueaba ante sus ojos estupefactos y salvajes. (173)

Esta explicación del sentido del eco le otorga profundidad al fenómeno como indicación de una fuente oculta y permanente de lo imprevisible, posible origen de la "retorcida", "escabrosa", "desconocida" figura que persigue a Balta en toda superficie reflejante, sustituyendo a su imagen cotidiana. La naturaleza, por medio de su peculiar "fabla salvaje", le habla a Balta sobre otro aspecto de sí mismo, su identidad primigenia. Se trata de una anagnórisis que el personaje no acepta, pues él, a diferencia de Narciso, busca ser idéntico a sí mismo. No se ve, porque otra presencia se sobrepone vagamente a su imagen. Palimpsesto insoportable para Balta. Cuando este cae al abismo, no se sumerge en el agua, como Narciso, sino que cae hacia su eco, hacia su foco de origen.

Todo armoniza cuando el desastre ha sido desencadenado: los animales anuncian desgracia; las premoniciones en los personajes tienen que ver con desintegración. Ecos, espejos, reflejos, parásitos, parcas, destino, tragedia, son tan solo instrumentos de una voluntad universal. Por su parte, el narrador con su parafernalia verbal da cuenta de la catástrofe. No hay salida para Balta. Condenado a desaparecer, a no tener continuidad, a suprimir su progenie.

Las deformaciones del modernismo ilustran una condena similar. Se abaten a sí mismas, absorbidas por los nuevos tiempos. Pero el parásito modernista todavía sobrevive en Fabla salvaje. En esta novela coexiste un estilo sobrio, moderado, que no llama la atención sobre sí mismo, junto a otro sumamente llamativo, enfático, cultista, típicamente modernista. En cuanto al estilo, la crítica suele asumir Fabla salvaje como una transición hacia el realismo en Vallejo. Carlos Eduardo Zavaleta, en 1988, ve en la prosa de esta novela que "Vallejo está 
limpio de la retórica de Escalas, descree de los artificios y su frase directa se ha logrado ya" (986). En otro momento previo, se refiere al "barroquismo que ha de abandonar desde Fabla salvaje en adelante" (985). Sobre este último caso, Zavaleta corrige su opinión en el artículo "Hacia la novela andina" (2007): "el narrador [...] prefirió darnos el proceso mental de una desviación psicopatológica, mediante la alternancia de un estilo barroco, expresionista, y de otro estilo directo y coloquial" (148). Ahora el crítico opta por la descripción de una alternancia estilística. Por su parte, Edmundo Bendezú considera que en Fabla salvaje se da un proceso que conduce hacia el realismo: "una prosa que en un movimiento centrípeto de su lengua literaria está agotando todas las posibilidades del modernismo, para luego volverse en un movimiento centrífugo hacia la prosa realista de El tungsteno (1931)" (136). Ricardo Silva-Santisteban afirma que, en Fabla salvaje, Vallejo "logró un afinamiento de su prosa de ficción mediante una expresión más espontánea carente de los excesos barrocos de Escalas" (XXI). En general, se asume que Fabla salvaje es el punto de cambio hacia el realismo. Debe tomarse en cuenta que la futura orientación hacia el estilo realista no obedece a una dinámica interna y autónoma, pues tiene que ver con la ideología que Vallejo adoptará en Europa.

En el cuento titulado "Mirtho", el narrador parodia el estilo cultista del discurso de un personaje:

Orate de candor, aposéntome bajo la uña índiga del firmamento y en las 9 uñas restantes de mis manos, sumo, envuelvo y arramblo los dígitos fundamentales, de 1 en fondo, hacia la más alta conciencia de las derechas.

Orate de amor, con qué ardentía la amo.

Yo la encontré, al viento el velo lila, que iba diciendo a las tiernas lascas de sus sienes: "Hermanitas, no se atrasen, no se atrasen...". Alfaban sus senos, dragoneando por la ciudad de barro, con estridor de mandatos y amenazas (100).

Entre otros términos llamativos que incluye esta intervención, seleccionamos: "sangre estética", "euritmia", “carnatura", "lombar", “apeala", "metalla", "halconados", "aquilinos", "tubulado", "intercolumnio", "hipogeo", "neorama" (101-102). Todo este discurso, calificado como jerigonza por el narrador, merece la burla de este: "tales cosas decía ayer un joven amigo mío, mientras con él discurríamos por el jirón de la Unión. Yo me reía a carcajada limpia" (102). El siguiente pasaje de El unigénito es otra muestra irónica de estilo cultista: "en la mesa el señor Lorenz, ovalando un mordisco episcopal sobre el sabroso choclo de mayo, que deshacíase y lactaba, de puro tierno, entre los cuatro dígitos del tenedor argénteo" (46).

Específicamente, en Fabla salvaje no hay una utilización irónica del estilo cultista. El tono con el que se lo aplica es grave. Si se trata de parodia, es parodia en serio. Los sucesos del relato son valorados constantemente por el narrador, quien está en diálogo con el destino. Figura locuaz, el narrador anuncia, señala los signos, prepara el desenlace, ve lo que los personajes no ven, interpreta lo que ellos no pueden interpretar. Sus párrafos concluyen en puntos suspensivos, dejando abierta la serie de consideraciones y especulaciones. Frente a unos personajes iletrados, el narrador expone un universo complejo a través de su habla hiperculta, plena de alusiones clásicas que, en ocasiones, se hallan en consonancia con la participación de algunos mitos grecolatinos. Su omnisciencia asume un perfil coral cuyas funciones van más allá de lo acostumbrado en los coros del teatro trágico griego. Es un voyeur que se exhibe a través de una serie de intervenciones altamente performativas. Y no 
deja de ser un otro en el lenguaje, con su lengua extraña que examina y enjuicia acciones y personajes desde su perspectiva oracular.

Cuando Balta logra verse en un nuevo espejo, la voz narrativa comenta:

Era su propia imagen la que él veía ahora, su imagen y no otra. Pero tuvo la sensación inexplicable y absurda de que el diseño de su persona en el cristal operó en ese brevísimo tiempo una serie de vibraciones y movimientos faciales, planos, sombras, caídas de luz, afluencias de ánimo, líneas, avatares térmicos, armonías imprecisas, corrientes internas y sanguíneas y juegos de conciencia tales, que no se habían dado en su ser original. ¡Desviación monstruosa, increíble, fenomenal! Desdoblamiento o duplicación extraordinaria y fantástica, morbosa acaso, de la sensibilidad salvaje, plena de prístinos poros receptivos de aquel cholo, en quien, aquél día bárbaro de altura y de revelación, la línea horizontal que iba desde el punto de intersección de sus dos cejas, desde el vértice del ángulo que forman ambos ojos en la visión, hasta el eje de lo invisible y desconocido, se rajó de largo a largo, y una de esas mitades separándose fue de la otra, por una fuerza enigmática pero real, hasta erguirse perpendicularmente a la anterior, echarse atrás, como si alcanzase la más alta soberanía y adquiriese voz de mando, caer por último a sus espaldas, empalmarse a la horizontalidad de la otra mitad, y formar con ella, como un radio con otro, un nuevo diámetro de humana sabiduría, sobre el eterno misterio del tiempo y del espacio... (168).

Abundan en el narrador las frases cargadas de elementos alusivos a lo fatal, con el propósito de crear una atmósfera fantasmagórica en la que la sensación de lo ineluctable anuncia una catástrofe: "una suerte de aviso misterioso", "una mala sombra" (151), "alguna desgracia", "rojo de presentimiento", "mala suerte, mala suerte" (152), "color de bilis muerta" (154), "misterioso y atroz presentimiento" (159), "poseído de un enorme terror" (163), "tragedia" (163, 173), "sutil inquietud de presagio", "estremecimientos de zozobra y terror", “impresión funesta”, “iOh la medrosa voz animal, cuando graves desdichas nos llegan!" (165), "hórrido presagio" (170), “infortunio" (176), "terror infinito" (178), "sublime trascendencia dramática" (180), "horrorosa, espeluznante” (182).

La insistencia en lo premonitorio, expone la intencionalidad de imponer un perfil trágico a los acontecimientos. A su vez, el insistente acorde del terror modulado por lo horrible y el miedo apuntala la atmósfera de extrañeza y angustia.

Antonio Fernández Molina explica la relación de los modernistas con las palabras: "las trataron y trabajaron, en buena medida, como objetos, casi como a seres con vida propia, e hicieron una especie de exhibición de las palabras, cual si las colocaran en vitrinas" (1982: 23-24).

Retomemos algunas de estas palabras en Fabla salvaje: "lapídea" (152), "áureo", "lancinante" (155), "púber", "íncubo", "pífano", "ludiendo", "basáltica", "verecundia", “índiga" (156), "triptolémicas"4, "excrementido" (164), "verticilar" (165), "avatares" (168), “cogitabundo" (174), "turquí" (182). Es claro el predominio en este léxico del enfático acento esdrújulo.

Como se puede apreciar, una nueva acepción del término fabla concierne ahora a estilo, al estilo de la voz narrativa. La novela corta, por su extensión, permite el empleo de esta clase de lenguaje. No se sostendría en novela de formato mayor.

\footnotetext{
4 "Faenas triptolémicas", alusión clásica que se refiere al trabajo con el trigo. Rubén Darío en "Salutación del optimista" había usado "labor triptolémica" (1949: 24).
} 


\section{Bibliografía}

\section{Obras citadas}

ANÓNIMO (2008): Poema de Mio Cid. Madrid, Cátedra.

BENDEZÚ AYBAR, Edmundo (1992): La novela peruana. De Olavide a Bryce. Lima, Editorial Lumen.

DARÍO, Rubén (1949): Cantos de vida y esperanza. Madrid, Afrodisio Aguado, S. A.,

DÍAZ VIANA, Luis (1986): "El juglar ante su público. Diversas formas de la actuación juglaresca". Revista de Folklore 69 (1986): 97-103.

DIEZ-CANSECO, José (2004): Narrativa completa. Lima, Pontificia Universidad Católica del Perú.

FERNÁNDEZ MOLINA, Antonio (1982): Antología de la poesía modernista. Madrid, Júcar.

RUIZ, Juan (2006): El libro de buen amor. Madrid, Cátedra.

SILVA-SANTISTEBAN, Ricardo. (1999): "La narrativa de César Vallejo". En César Vallejo, Narrativa completa. Lima, Pontificia Universidad Católica del Perú: XV-XXXI.

VALLEJO, CÉSAR (1999): Narrativa completa. Ed. Ricardo Silva-Santisteban y Cecilia Moreano. Lima, Pontificia Universidad Católica del Perú.

--- (2002): "La megalomanía de un continente". En César Vallejo, Artículos y crónicas completos. Tomo II. Ed. Jorge Puccinelli. Lima, Pontificia Universidad Católica del Perú: 691-693.

ZAVALETA, Carlos Eduardo (1988): “La prosa de César Vallejo". Cuadernos Hispanamericanos 456-457 (1988): 981-990.

--- (2007): “Hacia la novela andina”. Letras (78) 113 (2007): 145-156.

\section{Obras mencionadas}

BRITTON, Robert K. (2016): The poetic and real world of César Vallejo. A struggle between art and politics. Brighton, Sussex Academic Press.

GARCÍA, Mara L. (2009): "Lo inadmisible y retazos fantásticos en la narrativa vallejiana". ConNotas. Revista de crítica y teoría literarias 11 (2009): 199-210. DOI: https://doi.org/10.36798/critlit.v0i11.173

GONZÁLEZ MONTES, Antonio (2011): “Prólogo". En César Vallejo, Cuentos y novelas. Lima, Universidad de Ciencias y Humanidades, Fondo Editorial: 9-49.

GONZÁLEZ VIGIL, Ricardo (2012): "Prólogo". En César Vallejo, Narrativa completa. 2. a ed. aumentada y corregida. Lima, Ediciones Copé: 7-51. DOI: https://doi.org/10.31819/9783954870547-001

JÖERGER WEIRAUCH, Gisela (2001): “Fabla Salvaje”. En Wilfredo Kapsoli (ed.), César Vallejo en la crítica internacional. Lima, Universidad Ricardo Palma: 101-122.

SICARD, Alain (2015): "El doble en Fabla salvaje y en «Individuo y sociedad»". En su libro César Vallejo. El poeta de la carencia. Lima, Editorial Cátedra Vallejo: 103-109. 
VALLE-INCLÁN, Ramón del (1980): Romance de lobos. Madrid, Espasa-Calpe.

VALLEJO, CÉSAR (1998): Poemas completos. Introducción, edición y notas de Ricardo González Vigil. Lima, Ediciones Copé.

(C) Eduardo Hopkins Rodríguez

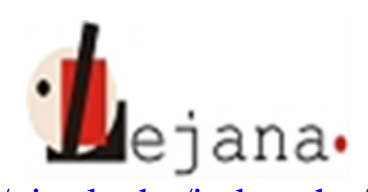

http://ojs.elte.hu/index.php/lejana

Universidad Eötvös Loránd, Departamento de Español, 1088 Budapest, Múzeum krt. 4/C 